\title{
THE ASSOCIATION OF RENAL AND GASTRIC DISORDERS WITH CONSTANCY OF THE URINARY REACTION
}

BY ROGER S. HUBBARD

(From the Laboratories of the Clifton Springs Sanitarium and Clinic, Clifton Springs, New York)

(Received for publication January 23, 1930)

It has been said that determinations of the alkaline tide in urine are of value in the study of two entirely distinct clinical conditions. One of these is associated with diseases of the stomach. Bence-Jones $(1,2)$ who seems to have been the first to describe diurnal variations in the acidity of urine, believed that they were associated with the secretion of acid into the stomach. Many physiologists have held similar views, $(3,4)$ and a number of different workers have suggested that an absence of changes in the reaction of urine means that the stomach does not secrete hydrochloric acid, $(5,6,7)$.

Leathes, $(8,9)$ McCorvie, (10) and others have taken an entirely different view of the problem. They believe that disease of the kidneys is usually, if not always, responsible for an absence of the alkaline tide. According to them relative over-ventilation through the lungs is the cause of the rhythmical changes in the reaction of the urine. When the kidneys are diseased the urine fails to reflect the changes in the blood induced by hyperpnoea, and its reaction is relatively constant. There seems to be no extensive series of cases in the literature in which the relationships of urinary reaction to both gastric and kidney abnormalities are considered in the same patients. Such a study is presented in this article.

Alkaline tide determinations have been made in this institution upon 296 subjects by the following technique. At seven o'clock the patient was aroused, and the night urine voided and, in most instances, discarded. Specimens were collected at hourly intervals thereafter until one o'clock. The reaction of these was determined by a colorimetric method. A meal, usually consisting of a glass of milk, a glass of water, two slices of toast with butter, and an egg, was fed between 
eight and nine o'clock. Most of the subjects were suffering from gastric disorders, and in many instances the presence of achylia gastrica was suspected.

The present discussion is based upon 173 of these patients who failed to show an alkaline tide as defined by Munford and Hubbard (5). These authors consider that a tide is present when the reaction of any specimen is more alkaline than that of one collected earlier in the experimental period by $1.0 \mathrm{pH}$, or when the reactions of any two specimens are more alkaline than a previous one by $0.5 \mathrm{pH}$. This definition of a tide certainly cannot be considered wholly satisfactory, but it serves as a convenient method for separating those tests in which there was at most a slight tide from those in which there was a more definite one.

The clinical histories and laboratory findings of these 173 patients were reviewed to determine the incidence of gastric and renal disorder. Eleven histories were not available. Gastric analyses were done upon 118 patients. In 78 hydrochloric acid was absent from the gastric juice; in 15 there was a marked hypochlorhydria, and only 25 showed an approximately normal concentration of acid after the test meal.

Among 162 patients whose urine showed little or no tendency toward the development of alkalinity during the morning there were many cases of achlorhydria and hypochlorhydria. What was the incidence of kidney disease in the series? In only 24 instances did the diagnoses suggest that circulatory or renal failure might have been present. These diagnoses included two cases of rheumatic and eleven of arteriosclerotic heart disease. Of the latter group two showed signs of congestive failure and three had auricular fibrillation. There were three cases with diagnoses of chronic nephritis, one of which was associated with hypertension and arteriosclerosis. Hypertension was diagnosed four times and arteriosclerosis three times. One diagnosis read pernicious anemia with heart block. It is evident that marked cardiovascular-renal disease occurred rather infrequently.

This evidence is supported by the available determinations of urea in the blood and of the rate at which phenolsulphonephthalein was excreted. The former study was carried out 27 times. The average value was $16.5 \mathrm{mgm}$. of urea nitrogen per $100 \mathrm{cc}$. of blood. In only four patients were values greater than $20 \mathrm{mgm}$. found. The phenol- 
sulphonephthalein test was done on 43 patients. The mean value of these was 50 per cent. No patient excreted less than 28 per cent of the dye in two hours, and only 7 of them less than 40 per cent during that period. More than half of the subjects excreted over 50 per cent -a figure which should almost certainly be considered normal when the dye is given intramuscularly and the urine is not collected through a catheter.

It seemed worth while to take into consideration the blood pressure readings of the group. The average values were systolic 135 and diastolic $76 \mathrm{~mm}$. There were only 7 instances in which the systolic pressure was over 180 and the same number with diastolic readings over $100 \mathrm{~mm}$. The figures certainly are not high.

Recently (11) it has been shown that there are two separate periods of increased urinary alkalinity during the morning. One of these occurs before any meal is fed and is probably due to respiratory adjustment to the activities of the day. The other develops later in the morning, and is caused, according to the author's view, by the secretion of hydrochloric acid into the stomach. The method by which the cases in this series were selected has confined the study to those showing an absence of the second tide. The results have also been analyzed to determine the relationship between nephritis and a urinary alkalinity developing before any meal is fed because the work of Leathes $(8,9)$ and McCorvie (10) suggests that such a study may be profitable. For this purpose those cases in the series already discussed in which the reaction of the night urine was determined have been considered separately. Such figures were available for 130 patients. In 15 of them the value of the $\mathrm{pH}$ representing the night urine was 7.0 or higher. These tests have been discarded because development of further alkalinity under such conditions seems improbable. Fortyfive showed a respiratory tide as defined by the author; that is the night urine was more acid by at least $0.5 \mathrm{pH}$ than that collected immediately after awakening. The remaining 70 patients failed to show either the gastric or respiratory tide.

The incidence of achlorhydria among these 70 subjects was approximately the same as in the whole series. Kidney disease, however, seemed to be present somewhat more frequently in the smaller group. Although less than half of the cases showed an absence of the early 
morning period of alkalinity this group provided seventeen of the twenty-four diagnoses which suggest the presence of cardiovascularrenal disease. These seventeen included all three of the cases of chronic nephritis, six of those with arteriosclerotic heart disease, four with arterioclerosis, and three with hypertension. However, since there were 53 cases out of the 70 for whom no such diagnoses were made, the difference between the groups with and without early alkaline tide is not striking. The routine urine findings agreed well with the clinical diagnoses. There was a somewhat higher incidence of marked abnormalities in the series without early alkaline tide, for five of the six patients who excreted more than a trace of albumin were included. Two of the four patients with red blood cells and 15 of the 27 with casts also showed no early period of alkalinity. On the other hand 28 of these seventy patients showed nothing abnormal in the urine at any time, and 10 others excreted only an occasional faint trace of albumin. Blood urea determinations, studies of the rate at which phenolsulphonephthalein was excreted, and blood pressure readings were almost exactly the same in the small series of 70 as they were in the large one of which it formed a part.

In a series or cases showing an absence of the characteristic alkaline tide after a meal achlorhydria occurred rather frequently, but there was little evidence of the presence of cardiovascular-renal disease. An absence of the early morning respiratory tide was somewhat more frequently associated with the conditions last named, but in a large proportion of the cases which showed no change of any sort in the urinary reaction there was no sign of renal or circulatory involvement. Since, however, the cases studied were picked from those in whom the presence of an abnormal gastric condition was suspected, and not from those showing lowered kidney function, care must be taken in drawing conclusions from the results. The conclusions may properly be stated as follows: 1st, relative constancy in reaction of the morning urine is often associated with an absence of hydrochloric acid from the gastric juice; 2nd, constancy in the reaction of the morning urine frequently occurs when no impairment of renal function and no signs of kidney disease can be demonstrated; 3rd, although there is some evidence that an absence of the early morning period of alkalinity may be associated with diseases of the kidneys the relationship is not an essential one. 


\section{BIBLIOGRAPHY}

1. Bence-Jones, H., Phil. Tr. Roy. Soc. London, 1845, cxxxv, 335. (Through Fiske (4)).

2. Bence-Jones, H., Phil. Tr. Roy. Soc. London, 1849, cxxxix, 235. (Through Fiske (4)).

3. Campbell, J. A., Biochem., J., 1920, xiv, 603. Ammonia Excretion, Aminoacid Excretion, and the Alkaline Tide in Singapore.

4. Fiske, C. J., J. Biol. Chem., 1921, xlix, 163. Observations on the "Alkaline Tide" After Meals.

5. Munford, S. A. and Hubbard, R. S., J. Am. Med. Assoc., 1926, Ixxxvii, 922. The Alkaline Tide in Achlorhydria.

6. Ackman, F. D., Canad. Med. Assoc. J., 1925, xv, 1099. The Relation Between Gastric Acidity and the Hydrogen Concentration of the Urine with a Study of the Effect of Histamine.

7. Davies, D. T., Brit. J. Exp. Path., 1929, x, 1. Some Observations on Gastric Secretion and Its Relationship to the Urinary Reaction.

8. Leathes, J. B., Brit. Med. J., 1919, ii, 165. Renal Efficiency Tests in Nephritis and the Reaction of the Urine.

9. Leathes, J. B., Lancet, 1920, ii, 933. Renal Function, a Determination of Its Degree.

10. McCorvie, J. E., J. Clin. Invest., 1926, ii, 35. Studies on the Morning Alkaline Tide of Urine in Normal Persons and in Patients with Nephritis.

11. Hubbard, R. S., J. Biol. Chem., 1929, lxxxiv, 191. The Reaction of the Morning Urine. 